\title{
Surgical decision making for symptomatic pelvic organ prolapse: evidence-based approach
}

\author{
Myung Jae Jeon \\ Department of Obstetrics and Gynecology, Seoul National University College of Medicine, Seoul, Korea
}

Surgery is the mainstay of treatment for symptomatic pelvic organ prolapse (POP), and a variety of procedures can be performed to correct POP. When deciding on the proper surgical procedure, the surgeon must take into consideration the individual patient's risk for surgical complication and prolapse recurrence and her preference. This review will discuss the key issues faced in the surgical decision-making process for POP and recommendations based on the current scientific evidence.

Keywords: Decision making; Pelvic organ prolapse; Surgery

\section{Introduction}

Surgery is the mainstay of treatment for symptomatic pelvic organ prolapse (POP). Epidemiologic studies have shown that women have an $11-19 \%$ risk of undergoing operation for POP during their lifetime [1-3], and up to one third of them undergo additional operation for disease recurrence [1].

There are a variety of procedures available for the surgical treatment of POP. The choice of procedure is frequently determined by the surgeon's training and expertise, but no single procedure fits to all patients. When deciding on the proper surgical procedure to be performed, the surgeon must take into consideration the individual patient's risk for surgical complication and prolapse recurrence and her preference [4].

This review will discuss the key issues faced in the surgical decision-making process for symptomatic POP and recommendations based on the current scientific evidence.

\section{Reconstructive versus obliterative surgery}

If a woman has an isolated anterior or posterior vaginal wall prolapse without apical prolapse, surgical decision-making is easy. Traditional anterior or posterior colporrhaphy can be performed to treat this condition. However, significant apical prolapse is almost always present in cases of advanced
POP (i.e., POP Quantification [POPQ] stage 3 or 4) [5], where surgeons have to decide whether to perform reconstructive or obliterative surgery to correct the prolapse. The choice depends on the medical condition and sexual function of the patient.

Reconstructive surgery corrects the prolapse while restoring the normal vaginal anatomy, whereas obliterative surgery does so by closing off the vaginal canal either partly (LeFort's colpocleisis) or totally (total colpocleisis) [6]. Therefore, reconstructive surgery is appropriate for a woman who is sexually active or may be sexually active in the future. However, POP usually involves multiple anatomical sites (apical, anterior, posterior), and therefore, extensive dissection and long operating time are needed for reconstructive surgery. Fragile, older women cannot tolerate this procedure [7-9]; hence, less

Received: 2019.03.06. Revised: 2019.04.22. Accepted: 2019.05.09. Corresponding author: Myung Jae Jeon

Department of Obstetrics and Gynecology, Seoul National University College of Medicine, 103 Daehak-ro, Jongno-gu, Seoul 03080, Korea

E-mail: jeonmj@snu.ac.kr https://orcid.org/0000-0001-5582-1488

Articles published in Obstet Gynecol Sci are open-access, distributed under the terms of the Creative Commons Attribution Non-Commercial License (http://creativecommons. org/licenses/by-nc/3.0/) which permits unrestricted non-commercial use, distribution, and reproduction in any medium, provided the original work is properly cited.

Copyright $\odot 2019$ Korean Society of Obstetrics and Gynecology 


\section{Obstetrics \& Gynecology Science}

Vol. 62, No. 5, 2019

invasive, obliterative surgery may be an appropriate option for these women. One large population-based, retrospective cohort study showed that women 80 years and older who underwent obliterative surgery had lower rates of perioperative complications compared with those who received reconstructive surgery for prolapse (17.0\% vs. $24.7 \%, P<0.01)$ [8]. Additionally, obliterative surgery has an extremely low-risk of prolapse recurrence [10]. One retrospective cohort study showed that women 70 years and older who underwent obliterative surgery had a lower risk of prolapse recurrence (defined as POPQ stage $\geq 2$ ) compared with those who received reconstructive surgery for prolapse $(9.3 \%$ vs. $31.5 \%, P<0.01)$ [11].

\section{Decision-making in reconstructive surgery}

If reconstructive surgery is planned, surgeons should make an effort to identify and correct all support defects requiring repair. There is growing recognition that adequate support for the vaginal apex is essential for a durable surgical repair. Because of the significant contribution of the vaginal apex to anterior and posterior vaginal support $[5,12]$, surgical correction of the anterior and posterior walls may fail unless the apex is adequately supported. One large populationbased, retrospective cohort study showed that concomitant apical suspension at the time of anterior or posterior colporrhaphy could significantly reduce the reoperation rates for recurrent prolapse within 10 years [13]. Therefore, apical suspension procedures should be included in the majority of pelvic reconstructions. Although there are no consensus statements or guidelines about the degree of apical support severe enough to warrant surgical correction, the descent of the vaginal apex at least halfway into the vaginal canal (i.e., POPQ point $C>-1 / 2 \times$ total vaginal length) needs to be corrected because it is closely linked with prolapse symptoms [14].

\section{Surgical route for apical suspension: abdominal versus vaginal}

Apical suspension procedures can be performed either transvaginally or abdominally. Abdominal procedures, including sacrocolpopexy (SCP) and uterosacral ligament suspension, can be performed via laparotomy or laparoscopy (with or without robotic assistance). Transvaginal procedures include native tissue repair (uterosacral ligament suspension, sacrospinous ligament fixation, or iliococcygeus suspension) and mesh repair [15]. The choice of an apical suspension procedure should be individualized to the specific patient because each procedure carries its own risk and benefit.

A recent Cochrane systematic review of 6 randomized controlled trials (RCTs) has demonstrated that vaginal procedures are associated with a higher risk of subjective recurrence (risk ratio $[R R], 2.11$; 95\% confidence interval $[\mathrm{Cl}], 1.06-4.21$ ), anatomical recurrence (RR, 1.89; $95 \% \mathrm{Cl}, 1.33-2.70)$, and repeat surgery for prolapse (RR, 2.28; $95 \% \mathrm{Cl}, 1.20-4.32$ ) compared with SCP, with a shorter operating time (mean difference, -21.49 minutes) being its only advantage. Comparing vaginal native tissue repair with transvaginal mesh (in $6 \mathrm{RCTs}$ ), there were no significant differences between the 2 groups even though mesh erosion rate was 18\% and surgery for mesh erosion was required in $9.5 \%$ after repair with transvaginal mesh [4]. Another systematic review including large case series and comparative studies (both randomized and nonrandomized) also showed results that favored SCP over vaginal native tissue repair in terms of anatomical success. However, adverse events such as thromboembolism ( $0.6 \%$ vs. $0.1 \%, P=0.03$ ), ileus or small bowel obstruction ( $2.7 \%$ vs. $0.2 \%, P<0.01$ ), and mesh or suture complications $(4.2 \%$ vs. $0.4 \%, P<0.01)$ occurred more frequently after SCP [16].

For SCP, minimally invasive approach (laparoscopy with or without robotic assistance) begins to gain popularity [17]. A recent systematic review of 12 studies including 1 RCT found that minimally invasive SCP and open SCP had a similar efficacy in terms of apical support and recurrence rate. However, minimally invasive SCP was associated with less blood loss (mean difference, $-113.27 \mathrm{~mL}$ ) and shorter hospital stay (mean difference, -1.57 days) even though it required a longer operating time (mean difference, +87.47 minutes). There were no differences in other intraoperative and postoperative complication rates [18]. The conventional laparoscopic SCP has also been compared to robotic SCP in 2 RCTs and 5 nonrandomized comparative studies. A systematic review of these studies found that both approaches were equally effective in correcting the prolapse, but laparoscopic SCP was more efficient in terms of operating time and cost compared to robotic SCP [19].

Given the current data, SCP may be more appropriate for 


\section{Obstetrics \& Gynecology Science}

Myung Jae Jeon. Surgical decision-making for prolapse

women with risk factors for prolapse recurrence, including young age, obesity, and advanced prolapse (POPQ stage 3 or 4) [20-23]. The preferred approach to SCP is laparoscopy. Vaginal native tissue repair benefits women who are at lowrisk for prolapse recurrence or at increased risk for gastrointestinal morbidity (e.g., old age and prior laparotomy) and mesh-related complications (e.g., chronic steroid use and smoking) [24-27]. Additionally, concomitant hysterectomy may increase the risk of mesh erosion after SCP [27-29]; therefore, vaginal native tissue repair is preferred over SCP when hysterectomy is performed for uterine prolapse. Transvaginal apical mesh has no advantage over vaginal native tissue repair.

\section{Uterine preservation versus hysterectomy for uterine prolapse}

When the apical suspension procedure is planned for uterine prolapse, the decision must be made whether to perform hysterectomy as a part of the procedure. Historically, hysterectomy has been considered a mainstay in the treatment of uterine prolapse, but the clinical data on its effect are limited. Additionally, there is a considerable desire for uterine preservation among patients. Recent studies showed that 36-60\% of women would decline hysterectomy if presented with an alternative to a hysterectomy-based prolapse repair with an equal efficacy, and $21 \%$ of women still preferred uterine preservation, even if uterine preservation was associated with inferior efficacy [30,31].

The most common procedures for correcting uterine prolapse with uterine preservation include sacrospinous hysteropexy (transvaginal), transvaginal mesh hysteropexy, uterosacral ligament uterine suspension (transvaginal or abdominal), and sacrohysteropexy with mesh (abdominal) [32]. Two recent systematic reviews including both randomized and nonrandomized trials compared hysteropexy with hysterectomy in terms of efficacy and complications $[33,34]$. Both studies have demonstrated that preservation of the uterus helps to reduce operating time, blood loss, and mesh exposure, provided that the surgical approach is the same. Regarding recurrent prolapse and reoperation for this condition, there was no significant difference between the groups among procedures using mesh even though there was a tendency for lower rates of recurrence and reoperation with hysterectomy. However, one study found a significant lower risk of recurrence with hysterectomy than with hysteropexy when the vaginal native tissue repair was performed, whereas the other study did not. This discrepancy might result from the difference in the study selection for review. The largest RCT found that sacrospinous hysteropexy was not inferior to vaginal hysterectomy and uterosacral ligament suspension for recurrent apical prolapse over 12 months [35]. However, this study was not included in the former review because of the inclusion of a high number of women with less advanced apical prolapse. Indeed, apical prolapse beyond the hymen (i.e., POPQ point $(>0$ ) has been reported as a significant risk factor for surgical failure after transvaginal hysteropexy $[36,37]$.

Recently, Dallas et al. [38] evaluated the association between hysterectomy at the time of prolapse surgery and the risk of undergoing subsequent prolapse surgery in a cohort of nearly 100,000 women. Hysterectomy at the time of prolapse surgery reduced the risk of repeat POP surgery at a median follow-up of 4 years, even when controlling for patient and surgical factors. However, there was a modest difference $(1-3 \%)$ in risk, and hysterectomy was associated with higher perioperative morbidity. Nonetheless, this result needs to be interpreted cautiously. Reoperation is the "tip of the iceberg," and the difference in the risk for prolapse recurrence might be significantly higher because patients tend to monitor the prolapse or use a pessary instead of undergoing a repeat surgery [39].

Given the current data, concomitant hysterectomy is recommended over uterine preservation at the time of apical suspension. Hysteropexy may be a reasonable alternative for women who have mild uterine prolapse and desire to preserve their uterus if they have no contraindications for uterine preservation [40] (Table 1).

Table 1. Contraindications for uterine preservation

\begin{tabular}{l}
\hline Contraindications \\
\hline Enlarged fibroids, adenomyosis, endometrial hyperplasia \\
Current or recent cervical dysplasia \\
Abnormal uterine bleeding or postmenopausal bleeding \\
BRCA1 and 2 mutations \\
Hereditary nonpolyposis colorectal cancer (Lynch syndrome) \\
Taking tamoxifen therapy \\
Unable to comply with routine gynecologic surveillance \\
Cervical elongation (relative contraindication)
\end{tabular}




\section{Obstetrics \& Gynecology Science}

Vol. 62, No. 5, 2019

\section{Concomitant repair of anterior or posterior prolapse}

As with apical prolapse, there is no consistent recommendation on which degree of anterior or posterior prolapse is to be corrected during reconstructive surgery. Nonetheless, when stage 2 or greater anterior or posterior vaginal prolapse (i.e., point $\mathrm{Ba}$ or $\mathrm{Bp} \geq-1$ ) is detected during the preoperative POPQ examination, several surgeons think that it needs to be addressed at the time of reconstruction.

An effective apical suspension can correct other sites of vaginal prolapse, but this is not always the case. Therefore, the decision must be made whether to perform an additional procedure to correct anterior or posterior prolapse. Simulated apical support during the preoperative POPQ examination can mimic the results following apical suspension and may help in this decision-making. One study has demonstrated that a significant proportion of anterior (55\%) and posterior prolapse (30\%) stage 2 or greater are resolved under simulated apical support [12]. Nonetheless, it remains unclear how the omission of anterior or posterior colporrhaphy for anterior or posterior prolapse corrected under simulated apical support in women undergoing apical suspension will affect the surgical outcome. Hence, further studies are needed to clarify this issue.

\section{Conclusion}

Surgical decision-making for POP requires a complex process. It is important that a surgeon provides adequate information on the risks and benefits of options available for correcting prolapse and guides a patient's decision-making. Recommendations based on the current scientific evidence are summarized as follows:

- Obliterative surgery should be considered as a first-line surgical procedure for fragile, older women with advanced POP who no longer desire vaginal intercourse. Otherwise, reconstructive surgery is recommended.

- Loss of apical support should be corrected at the time of reconstruction.

- The choice of an apical suspension procedure should be individualized to the specific patient. SCP is appropriate for women with risk factors for prolapse recurrence. The preferred approach to SCP is laparoscopy. Vaginal native tissue repair benefits women who are at low-risk for pro- lapse recurrence or at risk for gastrointestinal and meshrelated complications. Vaginal native tissue repair is also preferred over SCP when performing hysterectomy for uterine prolapse.

- Concomitant hysterectomy is recommended over uterine preservation at the time of apical suspension. Hysteropexy may be a reasonable alternative for women who have mild uterine prolapse and desire to preserve their uterus if they have no contraindications for uterine preservation.

\section{Conflict of interest}

No potential conflict of interest relevant to this article was reported.

\section{Ethical approval}

The study is not applicable to Institutional Review Board (IRB).

\section{Patient consent}

There is no need for patient consent in this review article.

\section{References}

1. Olsen AL, Smith VJ, Bergstrom JO, Colling JC, Clark AL. Epidemiology of surgically managed pelvic organ prolapse and urinary incontinence. Obstet Gynecol 1997;89:501-6.

2. Smith FJ, Holman CD, Moorin RE, Tsokos N. Lifetime risk of undergoing surgery for pelvic organ prolapse. Obstet Gynecol 2010;116:1096-100.

3. Løwenstein E, Ottesen B, Gimbel H. Incidence and lifetime risk of pelvic organ prolapse surgery in Denmark from 1977 to 2009. Int Urogynecol J Pelvic Floor Dysfunct 2015;26:49-55.

4. Maher C, Feiner B, Baessler K, Christmann-Schmid C, Haya N, Brown J. Surgery for women with apical vaginal prolapse. Cochrane Database Syst Rev 2016;10:CD012376. 


\section{Obstetrics \& Gynecology Science}

Myung Jae Jeon. Surgical decision-making for prolapse

5. Rooney K, Kenton K, Mueller ER, FitzGerald MP, Brubaker L. Advanced anterior vaginal wall prolapse is highly correlated with apical prolapse. Am J Obstet Gynecol 2006;195:1837-40.

6. Jelovsek JE, Maher C, Barber MD. Pelvic organ prolapse. Lancet 2007;369:1027-38.

7. Stepp KJ, Barber MD, Yoo EH, Whiteside JL, Paraiso MF, Walters MD. Incidence of perioperative complications of urogynecologic surgery in elderly women. Am J Obstet Gynecol 2005;192:1630-6.

8. Sung VW, Weitzen S, Sokol ER, Rardin CR, Myers DL. Effect of patient age on increasing morbidity and mortality following urogynecologic surgery. Am J Obstet Gynecol 2006;194:1411-7.

9. Bretschneider CE, Robinson B, Geller EJ, Wu JM. The effect of age on postoperative morbidity in women undergoing urogynecologic surgery. Female Pelvic Med Reconstr Surg 2015;21:236-40.

10. FitzGerald MP, Richter HE, Siddique S, Thompson P, Zyczynski H; Ann Weber for the Pelvic Floor Disorders Network. Colpocleisis: a review. Int Urogynecol J Pelvic Floor Dysfunct 2006;17:261-71.

11. Dessie SG, Shapiro A, Haviland MJ, Hacker MR, Elkadry EA. Obliterative versus reconstructive prolapse repair for women older than 70: is there an optimal approach? Female Pelvic Med Reconstr Surg 2017;23:23-6.

12. Lowder JL, Park AJ, Ellison R, Ghetti C, Moalli P, Zyczynski $\mathrm{H}$, et al. The role of apical vaginal support in the appearance of anterior and posterior vaginal prolapse. Obstet Gynecol 2008;111:152-7.

13. Eilber KS, Alperin M, Khan A, Wu N, Pashos CL, Clemens JQ, et al. Outcomes of vaginal prolapse surgery among female Medicare beneficiaries: the role of apical support. Obstet Gynecol 2013;122:981-7.

14. Lowder JL, Oliphant SS, Shepherd JP, Ghetti C, Sutkin G. Genital hiatus size is associated with and predictive of apical vaginal support loss. Am J Obstet Gynecol 2016;214:718.e1-718.e8.

15. Walters MD, Ridgeway BM. Surgical treatment of vaginal apex prolapse. Obstet Gynecol 2013;121:354-74.

16. Siddiqui NY, Grimes CL, Casiano ER, Abed HT, Jeppson PC, Olivera CK, et al. Mesh sacrocolpopexy compared with native tissue vaginal repair: a systematic review and meta-analysis. Obstet Gynecol 2015;125:44-55.

17. Haya N, Baessler K, Christmann-Schmid C, de Tayrac
$R$, Dietz V, Guldberg R, et al. Prolapse and continence surgery in countries of the Organization for Economic Cooperation and Development in 2012. Am J Obstet Gynecol 2015;212:755.e1-755.e27.

18. De Gouveia De Sa M, Claydon LS, Whitlow B, Dolcet Artahona MA. Laparoscopic versus open sacrocolpopexy for treatment of prolapse of the apical segment of the vagina: a systematic review and meta-analysis. Int Urogynecol J Pelvic Floor Dysfunct 2016;27:3-17.

19. Pan $K$, Zhang $Y$, Wang $Y$, Wang $Y$, Xu H. A systematic review and meta-analysis of conventional laparoscopic sacrocolpopexy versus robot-assisted laparoscopic sacrocolpopexy. Int J Gynaecol Obstet 2016;132:284-91.

20. Nieminen K, Huhtala $\mathrm{H}$, Heinonen PK. Anatomic and functional assessment and risk factors of recurrent prolapse after vaginal sacrospinous fixation. Acta Obstet Gynecol Scand 2003;82:471-8.

21. Whiteside JL, Weber AM, Meyn LA, Walters MD. Risk factors for prolapse recurrence after vaginal repair. Am J Obstet Gynecol 2004;191:1533-8.

22. Diez-Itza I, Aizpitarte I, Becerro A. Risk factors for the recurrence of pelvic organ prolapse after vaginal surgery: a review at 5 years after surgery. Int Urogynecol J Pelvic Floor Dysfunct 2007;18:1317-24.

23. Jeon MJ, Chung SM, Jung HJ, Kim SK, Bai SW. Risk factors for the recurrence of pelvic organ prolapse. Gynecol Obstet Invest 2008;66:268-73.

24. Whitehead WE, Bradley CS, Brown MB, Brubaker L, Gutman RE, Varner RE, et al. Gastrointestinal complications following abdominal sacrocolpopexy for advanced pelvic organ prolapse. Am J Obstet Gynecol 2007;197:78.e178.e7.

25. Jo YR, Kim JY, Jeon MJ. Significant gastrointestinal morbidity after sacrocolpopexy: the incidence and risk factors. Obstet Gynecol Sci 2014;57:304-9.

26. Lowman JK, Woodman PJ, Nosti PA, Bump RC, Terry CL, Hale DS. Tobacco use is a risk factor for mesh erosion after abdominal sacral colpoperineopexy. Am J Obstet Gynecol 2008;198:561.e1-561.e4.

27. Cundiff GW, Varner E, Visco AG, Zyczynski HM, Nager CW, Norton PA, et al. Risk factors for mesh/suture erosion following sacral colpopexy. Am J Obstet Gynecol 2008;199:688.e1-688.e5.

28. Tan-Kim J, Menefee SA, Luber KM, Nager CW, Lukacz ES. Prevalence and risk factors for mesh erosion after 


\section{Obstetrics \& Gynecology Science}

Vol. 62, No. 5, 2019

laparoscopic-assisted sacrocolpopexy. Int Urogynecol J Pelvic Floor Dysfunct 2011;22:205-12.

29. Akyol A, Akca A, Ulker V, Gedikbasi A, Kublay A, Han $A$, et al. Additional surgical risk factors and patient characteristics for mesh erosion after abdominal sacrocolpopexy. J Obstet Gynaecol Res 2014;40:1368-74.

30. Frick AC, Barber MD, Paraiso MF, Ridgeway $B$, Jelovsek $\mathrm{JE}$, Walters MD. Attitudes toward hysterectomy in women undergoing evaluation for uterovaginal prolapse. Female Pelvic Med Reconstr Surg 2013;19:103-9.

31. Korbly NB, Kassis NC, Good MM, Richardson ML, Book NM, Yip S, et al. Patient preferences for uterine preservation and hysterectomy in women with pelvic organ prolapse. Am J Obstet Gynecol 2013;209:470.e1-470. e6.

32. Ridgeway BM. Does prolapse equal hysterectomy? The role of uterine conservation in women with uterovaginal prolapse. Am J Obstet Gynecol 2015;213:802-9.

33. de Oliveira SA, Fonseca MC, Bortolini MA, Girão MJ, Roque MT, Castro RA. Hysteropreservation versus hysterectomy in the surgical treatment of uterine prolapse: systematic review and meta-analysis. Int Urogynecol J Pelvic Floor Dysfunct 2017;28:1617-30.

34. Meriwether KV, Antosh DD, Olivera CK, Kim-Fine S, Balk $\mathrm{EM}$, Murphy $\mathrm{M}$, et al. Uterine preservation vs hysterectomy in pelvic organ prolapse surgery: a systematic review with meta-analysis and clinical practice guidelines. Am J Obstet Gynecol 2018;219:129-146.e2.
35. Detollenaere RJ, den Boon J, Stekelenburg J, IntHout J, Vierhout ME, Kluivers KB, et al. Sacrospinous hysteropexy versus vaginal hysterectomy with suspension of the uterosacral ligaments in women with uterine prolapse stage 2 or higher: multicentre randomised non-inferiority trial. BMJ 2015;351:h3717.

36. Lin TY, Su TH, Wang YL, Lee MY, Hsieh CH, Wang KG, et al. Risk factors for failure of transvaginal sacrospinous uterine suspension in the treatment of uterovaginal prolapse. J Formos Med Assoc 2005;104:249-53.

37. Suh $\mathrm{DH}$, Jeon MJ. Risk factors for the failure of iliococcygeus suspension for uterine prolapse. Eur J Obstet Gynecol Reprod Biol 2018;225:210-3.

38. Dallas K, Elliott CS, Syan R, Sohlberg E, Enemchukwu E, Rogo-Gupta L. Association between concomitant hysterectomy and repeat surgery for pelvic organ prolapse repair in a cohort of nearly 100,000 women. Obstet Gynecol 2018;132:1328-36.

39. Jelovsek JE, Barber MD, Brubaker L, Norton P, Gantz M, Richter HE, et al. Effect of uterosacral ligament suspension vs sacrospinous ligament fixation with or without perioperative behavioral therapy for pelvic organ vaginal prolapse on surgical outcomes and prolapse symptoms at 5 years in the OPTIMAL randomized clinical trial. JAMA 2018;319:1554-65.

40. Gutman RE. Does the uterus need to be removed to correct uterovaginal prolapse? Curr Opin Obstet Gynecol 2016;28:435-40. 